\title{
Finite Element Modeling of Macro-Fiber Composite Actuators for Wing De-Icing Applications
}

\author{
Boutros Azizi ${ }^{*}$, Richard J. Prazenica, and Daewon Kim \\ Department of Aerospace Engineering, Embry Riddle Aeronautical University, \\ Daytona Beach, Florida 32114, USA \\ azizib@my.erau.edu,prazenir@my.erau.edu,kimd3c@my.erau.edu
}

\begin{abstract}
In this paper, a proposed de-icing technique is studied in which lightweight macrofiber composite (MFC) actuators are used to break the adhesive bond between the leading edge of a wing and an accumulated ice layer. The concept for this technique relies on the fact that when a structure is excited at its natural frequencies, the shear stress generated is highest for certain modes. This shear stress can be used, therefore, to break the adhesive shear bond of ice with the structure. Since MFC finite element models are currently unavailable, this paper presents the development of an MFC model based on a standard piezoceramic finite element that has been modified to model the characteristics of MFC. This MFC finite element model is validated using a unimorph cantilever beam for which analytical solutions can be derived for the natural frequencies as well as the static and dynamic tip deflections in response to voltage excitation. The finite element solution for this system is compared to analytical and experimental results, demonstrating the validity of the MFC model. The MFC finite element model is then used to study the proposed de-icing technique on a model of an aluminum leading edge of an airfoil section. An analysis of the mode shapes, locations, and number and width of MFC actuators is performed to find the best combination of parameters to generate the highest shear stress, and hence the most effective MFC actuator configuration for de-icing the leading edge. Finally, ice de-bonding is studied for different ice layer thicknesses and the total power consumption required for the proposed de-icing technique is calculated.
\end{abstract}

Keywords: macro-fiber composite, finite element analysis, wing de-icing

\section{Introduction}

Recent aviation research has focused on the subject of aircraft safety in severe weather conditions. During inclement weather, icing has been found to have significant negative effects on aircraft flight performance and has resulted in several fatal accidents [1-2]. Therefore, the prevention of ice formation (anti-icing) and the removal of ice buildup (deicing) are critical technologies for ensuring the safety of a wide range of aircraft. Icing primarily occurs on the leading edge of wings, tails, and the inside or outside of the engines.

Anti-icing and de-icing can be performed on both the ground and in flight. When an aircraft is at rest on the ground, de-icing is commonly achieved by spraying chemical fluid or hot water on the aircraft, or via forced-air de-icing [3]. In-flight anti-icing can be achieved by regularly maintaining the leading edge surfaces, which are prone to ice accumulation, at higher temperatures, an approach that consumes large amounts of energy [4]. Some of the in-flight de-icing techniques that are currently in use include the ElectroImpulse De-Icing (EIDI) method, which is usually applied to helicopter rotors [5], and the Electro-Mechanical Expulsion De-Icing System (EMEDS), which is based on generating high frequency vibrations [6]. The Pneumatic Impulse Ice Protection System (PIIP) utilizes a stretchable, fabric-reinforced elastomer deicing boot, which is inflated using 
high pressure air impulses supplied to flat reinforced tubes in order to remove ice from the wing [7]. These conventional in-flight de-icing and anti-icing techniques feature significant drawbacks such as high energy consumption and the addition of appendages to the aircraft structure that can add weight and affect aerodynamic performance.

The use of smart materials, such as shape memory alloys (SMA), piezoceramics, and macro-fiber composite (MFC), has been proposed by several researchers in order to address some of the shortcomings of conventional de-icing and anti-icing methods. Ingram et al. [8] developed a de-icing technique using sheets of shape memory alloy, material that undergoes a phase transition and contracts when heated, to induce vibrations and resulting shear stresses on the leading edge of a wing. Several researchers have developed and tested de-icing methods using piezoceramic actuators [9 - 13]. These investigations have included finite element modeling and analysis of leading edge wing structures and rotorcraft blades in order to determine the most effective modes of excitation to cause ice to de-bond from the structure. In several of these studies, piezoceramic actuators have been successfully employed in experiments to de-ice plates and aluminum leading edge surfaces. While these experiments have shown promising results, there are several issues to be resolved in order to employ piezoceramic actuators for the de-icing of aircraft structures, such as the difficulty associated with attaching brittle PZT actuators to the curved wing leading edge and their low strain efficiency.

This paper considers an approach to aircraft de-icing that entails using MFC actuators to excite the structure at one or more of its natural frequencies in order to generate shear stresses of sufficient magnitude to break the adhesive bond of ice with the structure. MFC is a layered, planar actuation material that consists of a rectangular cross-section with unidirectional piezoceramic fibers (PZT 5A) embedded in a thermosetting polymer matrix. The active fiber-reinforced layer is sandwiched between Kapton film layers and copper-clad materials that possess an interdigitated electrode pattern [14]. MFC has been used in different applications such as vibration control of an F-18 vertical stabilizer [15], large-deflection shape control including morphing wing technology [16], and energy harvesting using MFC as both a sensor and an actuator at the same time [17]. The MFC actuators and sensors used in the studies presented in this paper correspond to the P1 type devices with overall dimensions of $85 \times 14 \times 0.3 \mathrm{~mm}^{3}$, which operate based on the electromechanical coupling mechanism $d_{33}$. In the $d_{33}$ coupling effect, the induced polarization and the applied stress are in the 3-direction [18].

MFC actuators offer several potential benefits for de-icing applications. Some of these benefits are that MFC is very lightweight, it operates at a very low temperature, even below the freezing point, MFC can be fixed directly to the wing structure and it can conform to the wing structure without changing the form factor of the wing, it is capable of large, continuous deformations, eliminating the need for hinged control surfaces, and MFC deformation can be accurately controlled using appropriate voltage inputs, which can provide precise excitation at the desired natural frequency [19]. MFC actuators would add minimal weight and drag to an aerodynamic surface, which is significant for aircraft performance and fuel consumption. In related work, Wang et al. [20] applied MFC actuators for wing de-icing in simulation studies in which the actuators were used to excite the third mode of vibration of a leading edge wing structure. This excitation was shown to generate shear stresses that would be large enough to cause ice to de-bond from the structure.

Numerous experiments have been conducted to measure the adhesive shear strength of ice. The variation in testing methods, experimental procedures, and ice type has led to a large variation in the adhesive strength determined in these investigations. Raraty and Tabor [21] performed experiments at $-10^{\circ} \mathrm{C}$ and concluded that the interface strength of the ice is less than the strength of the ice itself. Loughborough [22] found that the adhesive shear strength of ice increases with decreasing temperature. In a study by 
Bascom et al. [23], the adhesive strength of ice was measured at $-6^{\circ} \mathrm{C}$, and it was determined that it significantly increases with increasing surface roughness. Jellinek [24] studied snow ice accumulation on a stainless steel substrate and found that the adhesive strength of ice is lower in shear than in torsion. Based on these studies, it was concluded that the shear strength of refrigerated ice ranges between $0.24 \mathrm{MPa}$ and $1.6 \mathrm{MPa}$, and it ranges lower, between $0.026 \mathrm{MPa}$ and $1.03 \mathrm{MPa}$, for wind tunnel impact ice testing due to aerodynamic loads. Since refrigerated ice is commonly used in de-icing experiments, the studies presented in this paper consider 1.6 MPa to be the maximum shear stress required to de-bond ice from an aluminum surface. Archer and Gupta [25] determined that the maximum adhesive tensile strength of refrigerated ice is around $300 \mathrm{MPa}$, which is two orders of magnitude greater than the shear stress; therefore, this paper focuses on de-icing techniques that generate shear stresses in order to break the shear bond of the ice-substrate interface.

It is important to note that, unlike piezoceramic material, models of which are incorporated into standard finite element software packages, there are currently no available finite element models of macro-fiber composite. Developing a suitable model of MFC actuators, therefore, is a central issue that must be addressed in order to study the proposed MFC-based de-icing application. A key contribution of this paper is the development of a finite element model of MFC actuators. In contrast to the approach taken by Wang et al. [20], in which a thermal-elastic analogy was used to model the MFC actuators, the MFC model developed in this paper is based on a modification of the standard piezoceramic finite element. In order to validate this MFC finite element model, a unimorph cantilever beam system is considered for which analytical expressions can be derived for the natural frequencies as well as the beam deflection resulting from static and dynamic voltage excitation. The finite element results are then compared to analytical and experimental results in order to assess the accuracy of the model.

This paper is organized as follows. Section 2 introduces the unimorph cantilever beam that is used as a prototype system for the development and validation of the MFC finite element model. Analytical expressions for the natural frequency and tip deflection in response to voltage excitation are presented for the purposes of comparison with finite element and experimental results. Section 3 then discusses the development of a finite element model of MFC actuators bonded to a structure using modifications to the standard ABAQUS piezoceramic element. Section 4 presents experimental results obtained for the unimorph cantilever beam, and a comparison of the analytical, finite element, and experimental results is provided in order to validate the MFC finite element model. After validating the MFC model, a finite element analysis of the de-icing of the leading edge of a wing using MFC actuators is performed in Section 5. This analysis includes determining the mode of excitation that is best suited for the de-icing application based on the level of shear stress generated for each excitation mode. Then, a trade study is conducted to determine the best placement, number, and width of MFC actuators to be used to excite the structure for de-icing. An ice de-bonding study is then performed to investigate the effectiveness of the MFC-based system for removing ice layers of varying thickness from the leading edge structure. The power consumption requirements of the proposed MFC de-icing system are also discussed. Finally, Section 6 provides a discussion of the results and conclusions. 


\section{Analysis of a Unimorph Cantilever Beam}

The MFC finite element model developed in this paper is validated on a system corresponding to a unimorph cantilever beam, which consists of an MFC actuator $(85 \mathrm{x}$ $\left.14 \times 0.3 \mathrm{~mm}^{3}\right)$ mounted to the top of an aluminum cantilever beam $\left(222 \times 14 \times 5 \mathrm{~mm}^{3}\right)$, as shown in Figure 1. This system is chosen because analytical models can be derived for the natural frequencies as well as the static and dynamic tip displacement resulting from voltage excitation. Therefore, results computed using the finite element model can be compared to both analytical and experimental results in order to assess the validity of the finite element model. In Figure $1, F$ represents the blocking force, which is the effective force generated at the tip due to the MFC actuation.

Table 1. Material Parameters of the MFC Actuators and Aluminum Beam

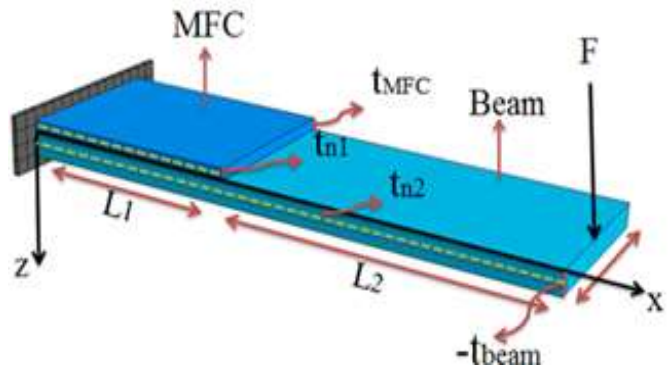

Figure 1. Unimorph Cantilever Beam

\begin{tabular}{|c|c|c|}
\hline MFC (Type P1) & Density & $5440 \mathrm{Kg} / \mathrm{m}^{3}$ \\
\hline \multirow{4}{*}{} & $\mathrm{E}_{1}$ & $30.35 \mathrm{E} 9 \mathrm{~Pa}$ \\
\cline { 2 - 3 } & $\mathrm{E}_{2}=\mathrm{E}_{3}$ & $15.85 \mathrm{E} 9 \mathrm{~Pa}$ \\
\cline { 2 - 3 } & $\mathrm{G}_{12}=\mathrm{G}_{13}=\mathrm{G}_{23}$ & $5.52 \mathrm{E} 9 \mathrm{~Pa}$ \\
\cline { 2 - 3 } & $\mathrm{v}_{12}$ & 0.31 \\
\cline { 2 - 3 } & $\mathrm{v}_{13}=\mathrm{v}_{23}$ & 0.16 \\
\cline { 2 - 3 } & $\mathrm{d}_{33}$ & $4.6 \mathrm{E}-10 \mathrm{C} / \mathrm{N}$ \\
\cline { 2 - 3 } & $\mathrm{d}_{31}$ & $-2.1 \mathrm{E}-10 \mathrm{C} / \mathrm{N}$ \\
\hline \multirow{7}{*}{$\begin{array}{c}\text { Aluminum } \\
\text { Beam }\end{array}$} & Density & $2700 \mathrm{~kg} / \mathrm{m}^{3}$ \\
\hline & $\mathrm{E}$ & 0.35 \\
\cline { 2 - 3 } & $\mathrm{E}$ & $70 \mathrm{E} 9 \mathrm{~Pa}$ \\
\hline
\end{tabular}

Table 1 presents the material parameters of the unimorph cantilever beam and the MFC actuators used for the numerical analysis.

\subsection{Natural Frequency}

In general, for a cantilever beam (without the MFC actuator), an analytical expression for the natural frequencies can be derived as [26]

$$
f_{i}=\frac{\lambda_{i}^{2}}{2 \pi L^{2}}\left(\frac{E I}{m}\right)^{1 / 2}, \quad \mathrm{i}=1,2,3,4 \ldots
$$

where $\lambda_{i}$ represent dimensionless natural frequency parameters, given by solutions to the equation

$$
\cos \lambda \cosh \lambda+1=0
$$

Applying Eq. (1), the natural frequencies for the first 5 modes are given in Table 2a. It should be mentioned here that the actuator patch is not taken into consideration due to its size and weight.

\subsection{Static Tip Displacement}

The static displacement of a unimorph cantilever beam can be expressed as [27].

$h(x)=\frac{1}{6}\left[\frac{F}{w D_{2}} x^{3}-\frac{3 F\left(L_{1}+L_{2}\right)}{w D_{2}} x^{2}-\left(\frac{1}{D_{1}}-\frac{1}{D_{2}}\right) \frac{3 F L_{1}}{w}\left(L_{1}+2 L_{2}\right) x+\left(\frac{1}{D_{1}}-\frac{1}{D_{2}}\right) \frac{F L_{1}^{2}\left(L_{1}+3 L_{2}\right)}{w}\right]$

where the blocking force $F$ is given by [27] 


$$
F=\frac{3 w E_{\text {beam }} t_{\text {beam }} E_{M F C} t_{M F C}\left(t_{\text {beam }}+t_{M F C}\right)}{4 L_{1}\left(E_{\text {beam }} t_{\text {beam }}+E_{M F C} t_{M F C}\right)} d_{33} \frac{V}{t_{M F C}}
$$

and $V$ is the applied voltage. $D_{1}$ and $D_{2}$ are the bending moduli per unit length over the lengths $L_{1}$ and $L_{2}$ denoted in Figure 1:

$$
\begin{gathered}
D_{1}=\frac{E_{M F C}{ }^{2} t_{M F C}{ }^{4}+E_{\text {beam }}{ }^{2} t_{\text {beam }}{ }^{4}+2 E_{M F C} E_{\text {beam }} t_{M F C} t_{\text {beam }}\left(2 t_{M F c}{ }^{2}+2 t_{\text {beam }}{ }^{2}+3 t_{M F C} t_{\text {beam }}\right)}{12\left(E_{M F C} t_{M F C}+E_{\text {beam }} t_{\text {beam }}\right)} \\
D_{2}=\frac{E_{\text {beam }} t_{\text {beam }}{ }^{3}}{12}
\end{gathered}
$$

The static tip displacement is computed for the cantilever aluminum beam using Eq. (3). The analytical static tip displacement is given in Table $2 \mathrm{~b}$ as a function of an applied voltage that is varied from $0 \mathrm{~V}$ to $1500 \mathrm{~V}$.

\subsection{Dynamic Tip Displacement}

Euler-Bernoulli beam theory can be applied to determine an analytical expression for the tip displacement of a cantilever beam subject to harmonic excitation [28]. EulerBernoulli theory is applicable to the cantilever beam considered in Figure 1 since the beam length is at least ten times as large as the width. A general solution for the beam deflection is given by [28]

$$
w(x, t)=\sum_{i=1}^{3} q_{i}(t) y_{i}\left(\frac{x}{L}\right)
$$

where $\left\{y_{i}\right\}_{i=1}^{3}$ are the mode shapes, given as [26]

$$
y_{i}\left(\frac{x}{L}\right)=\cosh \frac{\lambda_{i} x}{L}+\cos \frac{\lambda_{i} x}{L}-\frac{\sinh \lambda_{i}-\sin \lambda_{i}}{\cosh \lambda_{i}+\cos \lambda_{i}}\left(\sinh \frac{\lambda_{i} x}{L}+\sin \frac{\lambda_{i} x}{L}\right)
$$

and $\left\{q_{i}\right\}_{i=1}^{3}$ represent modal coordinates, given by [26]

$$
q_{i}(t)=\frac{1}{\omega_{d, i}} e^{-\zeta \omega_{n, i} t} \int_{0}^{t} F_{i}(\tau) e^{-\zeta \omega_{n, i} \tau} \sin \left(\omega_{d, i}(t-\tau)\right) d \tau
$$

It is well known that, for harmonic motion, the damping ratio $\zeta$ is a critical parameter. In order to solve Eq. (9), the value of the damping ratio must be assumed or calculated, which requires dynamic testing. In this case, the logarithmic decrement method is used to estimate the damping ratio of the structure. For simplicity, the damping ratio is considered fixed for all the modes and approximated to be $\zeta=0.093$. Using this value for the damping ratio, Table $2 \mathrm{c}$ lists the computed tip deflection of the cantilever beam under harmonic excitation at each of the first three natural frequencies, corresponding to 9.78 $\mathrm{Hz}, 54.12 \mathrm{~Hz}$ and $152.35 \mathrm{~Hz}$. It should be noted that these excitation frequencies correspond to the experimentally measured natural frequencies, as described in Section 3. The experimental frequencies are used for excitation because the analytical expression for the natural frequencies given in Eq. (1) accounts only for the aluminum substrate and not the MFC actuator. 


\section{Table 2. Analytical Results from the Aluminum Cantilever Beam Model}

(a) Natural Frequencies

\begin{tabular}{|c|c|}
\hline Mode \# & Natural Frequency (Hz) \\
\hline 1 & 8.50 \\
\hline 2 & 53.25 \\
\hline 3 & 149.07 \\
\hline 4 & 291.89 \\
\hline 5 & 482.99 \\
\hline
\end{tabular}

(c) Harmonic Tip Deflection

\begin{tabular}{|c|c|}
\hline $\begin{array}{c}\text { Natural } \\
\text { Frequency ( Hz) }\end{array}$ & Tip Deflection (m) \\
\hline 9.78 & 0.11 \\
\hline 54.122 & 0.01 \\
\hline 152.35 & 0.0011 \\
\hline
\end{tabular}

(b) Static Tip Deflection

\begin{tabular}{|c|c|}
\hline Voltage (V) & Tip Deflection (m) \\
\hline 0 & 0 \\
\hline 500 & 0.015 \\
\hline 1000 & 0.03 \\
\hline 1500 & 0.045 \\
\hline
\end{tabular}

\section{MFC Finite Element Model}

While piezoceramic finite element models have been developed and are included in several commercial FE software packages, currently there are no commercially available models for macro-fiber composite (MFC). Therefore, in this paper, a finite element model of MFC is developed in order to model the implementation of MFC actuators on the leading edge of a wing for de-icing. The MFC finite element model is developed in ABAQUS [29] through a modification of the standard piezoceramic element that is included in this software package. The MFC model is first developed for the unimorph cantilever beam system described in Section 2 in order to compare the results with those obtained from the analytical model and experimental results. After validating the MFC finite element model, the wing de-icing application is considered in Section 5.

\subsection{Finite Element Model}

A finite element model is developed of the cantilever beam subject to excitation by a unimorph MFC actuator. Type P1 MFC is modeled because it utilizes the $d_{33}$ effect for actuation; hence it has a larger piezoelectric strain coefficient as well as a higher range of operational voltages [19]. The MFC actuator is modeled using the reduced 20 nodes second-order quadratic piezoelectric brick (C3D20RE) and the cantilever aluminum beam is modeled using the reduced 20 nodes second-order quadratic brick (C3D20R). In this model, the MFC is attached to the cantilever beam at the clamped end using the TIE constraints method, with surface to surface bonding, which results in joining the degrees of freedom of both bodies. The epoxy is neglected, and it is assumed that the bonding is perfect between the MFC actuator and the aluminum beam. The ENCASTRE type is used as a mechanical boundary condition to rigidly fix the clamped side of the aluminum beam. For the electrical boundary condition, the bottom surface of the MFC is set as the ground $(0 \mathrm{~V})$. Because of the complex structure of MFC, which consists of 170 sections of electro-couples with $0.5 \mathrm{~mm}$ spacing, the MFC P1 electrodes have not been modeled in micro scale. Instead, a new method has been applied in this paper to simulate the real electrodes. Both surfaces of the Type P2 MFC are covered by electrodes [19]. Because it is difficult to model the interdigital electrodes in the Type P1 MFC, the MFC P1 is modeled as MFC P2 so that the electrodes on the top and bottom surface of the MFC P1 
are converted to a single large electrode that covers the whole surface, similar to the MFC P2 case (see Figure 2).

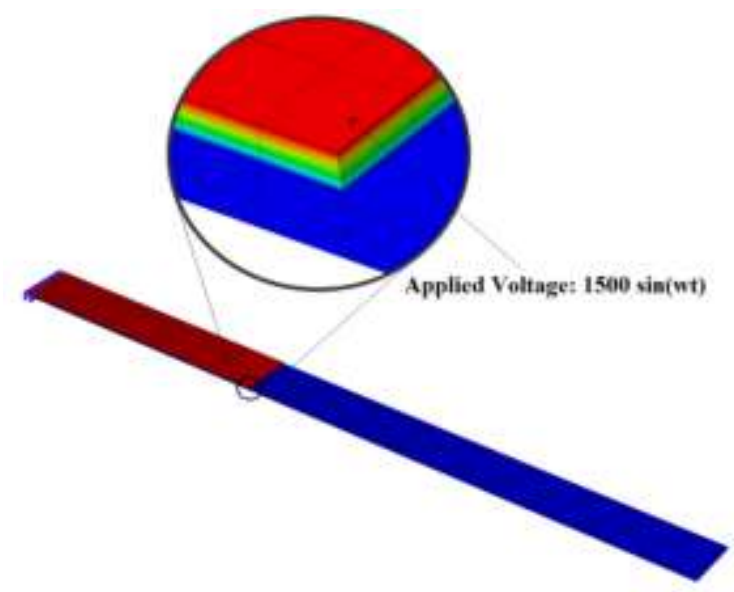

Figure 2. Finite Element Model of the MFC Electrodes

While applying this technique, it is important to ensure that the mechanical and electrical properties of the MFC P1 remain unchanged in the model. For the piezoelectric properties, the model must be constructed in such a manner that, when an input voltage is applied, the strain generated from the modeled MFC actuator is the same as the original Type 1 MFC. This leads to the following condition [30]:

$$
d^{\prime}{ }_{31} \frac{V}{t_{e}}=d_{33} \frac{V}{d_{e}}
$$

where $t_{e}=0.3 \mathrm{~mm}$ is the thickness of the MFC and $d_{e}=0.5 \mathrm{~mm}$ is the distance between two consecutive electrodes. Using the MFC properties from Table $1, d_{31}^{\prime}$ is computed to be $2.76 \times 10^{-10} \mathrm{CN}^{-1}$. This value is then used in the finite element model of the MFC actuator. In addition, constraint equations to model the electrodes must be defined [27]. These constraints ensure that on the electrode surface, the voltage degrees of freedom ( 9 total degrees of freedom are tested) of one node are equal to those of the other nodes (i.e., these constraints emulate the uniform potential of an electrode). After applying these constraint equations, a mesh refinement is performed and the required number of elements is found to be 4512 .

\subsection{Natural Frequency, Static and Dynamic Tip Displacement}

To compute the natural frequencies of the cantilever beam system, a twenty node quadratic brick with reduced integration is used (C3D20R) to model the beam. One of the short edges of the beam, corresponding to the rigidly clamped edge, is fixed by specifying zero degrees of freedom (ENCASTRE). After modeling the beam, a mesh refinement study was performed until little or no change in the computed natural frequencies was observed. It was determined that a mesh with 3080 elements provides good accuracy with a reasonable computation time. The first five natural frequencies obtained from the finite element analysis are given in Table 3a. According to the results, Modes 1, 2, 3 and 6 are found to be bending modes while Modes 4 and 5 are torsional modes.

A series of finite element simulations is performed for the static analysis of the cantilever tip deflection. A DC voltage using Dynamic Implicit generates the only force applied on the aluminum cantilever beam through the MFC actuator; this voltage ranged between 0 to $1500 \mathrm{~V}$ with $100 \mathrm{~V}$ increments. The load is applied on the top surface of the 
MFC. Since the applied load corresponds to a DC voltage, which leads to a small static deflection, the damping has only a small or negligible effect on the deflection; hence, the damping ratio is assumed to be zero in the static analysis. The computed static tip deflections for different driving voltages are summarized in Table $3 \mathrm{~b}$.

A steady state dynamic analysis is performed to predict the tip deflection under harmonic excitation at the natural frequencies. Damping has a critical effect on harmonic motion; therefore, the Rayleigh method is employed to estimate the damping ratio. The Rayleigh damping for the beam is expressed as [26]

$$
\xi_{i}=\frac{1}{2}\left(\frac{\alpha}{f_{i}}+f_{i} \beta\right)
$$

where $\alpha$ and $\beta$ are unknown parameters and $f_{i}$ is the natural frequency of the $i^{\text {th }}$ mode. To determine $\alpha$ and $\beta$, the damping ratios corresponding to the first two modes must be found. Using the logarithmic decrement method, these values were computed to be $\zeta_{1}=$ 0.093 and $\zeta_{2}=0.097$. Using the experimentally determined natural frequencies $f_{1}=$ $9.7842 \mathrm{~Hz}$ and $f_{2}=54.122 \mathrm{~Hz}$ (which account for the MFC actuator and sensor), as well as the two damping ratios $\zeta_{1}$ and $\zeta_{2}$ in Eq. (12), the unknown Rayleigh damping parameters are computed as $\alpha=1.52606$ and $\beta=3.06351 \times 10^{-3}$.

In order to perform the harmonic analysis, a sinusoidal electric potential of $1500 \mathrm{~V}$ is applied to the MFC actuator at each of the first three natural frequencies. It should be noted that the experimentally determined natural frequencies are used for excitation since, in contrast to the analytical model, the experimental values account for the presence of the MFC actuator. Table $3 \mathrm{c}$ presents the maximum tip displacement of the cantilever beam under sinusoidal loading at different excitation frequencies.

Table 3. Finite Element Results from the Aluminum Cantilever Model

(a) Natural Frequencies

\begin{tabular}{|c|c|}
\hline Mode \# & Natural Frequency (Hz) \\
\hline 1 & 8.55 \\
\hline 2 & 53.96 \\
\hline 3 & 150.12 \\
\hline 4 & 294.43 \\
\hline 5 & 487.32 \\
\hline
\end{tabular}

(c) Harmonic Tip Deflection (1500 V)

\begin{tabular}{|c|c|}
\hline $\begin{array}{c}\text { Natural } \\
\text { Frequency (Hz) }\end{array}$ & Tip Deflection (m) \\
\hline 9.78 & $1.119 \mathrm{E}-01$ \\
\hline 54.122 & $7.170 \mathrm{E}-03$ \\
\hline 152.35 & $7.602 \mathrm{E}-04$ \\
\hline
\end{tabular}

(b) Static Tip Deflection

\begin{tabular}{|c|c|}
\hline Voltage (V) & Tip Displacement (m) \\
\hline 0 & 0 \\
\hline 500 & 0.01473 \\
\hline 1000 & 0.02773 \\
\hline 1500 & 0.04159 \\
\hline
\end{tabular}




\section{Experimental Verification}

Experiments are performed on the aluminum cantilever beam to find the natural frequencies, tip deflections and output voltages (energy harvesting) in response to harmonic excitation. Comparisons are made between the data obtained using the analytical model, the finite element model, and experiments. The main purpose of this set of experiments is to validate the MFC finite element model developed in Section 3.

\subsection{Experimental Measurement of Natural Frequencies}

The total length of the beam tested is $0.23 \mathrm{~m}$, but when it is clamped, the length becomes $0.22 \mathrm{~m}$. The aluminum beam is clamped vertically so its weight has a negligible effect on the transverse bending. The test setup, shown in Figure 3, includes a DC power supply that provides voltage between $0 \mathrm{~V}$ and $5 \mathrm{~V}$ to a small, high-voltage amplifier. This amplifier converts DC voltage in the range of $0 \mathrm{~V}$ to $5 \mathrm{~V}$ into voltage between $-500 \mathrm{~V}$ and $1500 \mathrm{~V}$ and supplies the amplified voltages to the MFC type P1 actuator. The MFC actuator is bonded to the beam near the fixed edge using M-Bond 200 epoxy. The DC voltage input to the amplifier is regulated using a data acquisition (DAQ) system running LabVIEW software. In order to experimentally determine the modal response of the structure, a sine wave sweep input signal is generated and passed to the high voltage amplifier. The frequency of the sine wave is increased gradually from $1 \mathrm{~Hz}$ to $500 \mathrm{~Hz}$. It can be seen that when the excitation frequency corresponds to a natural frequency, the structure exhibits larger vibrations. To measure the response of the structure to the frequency sweep, a circular PZT sensor (radius $=3 \mathrm{~mm}$ ) located on the other side of the aluminum cantilever beam is used. This sensor is connected to the input of the DAQ system.

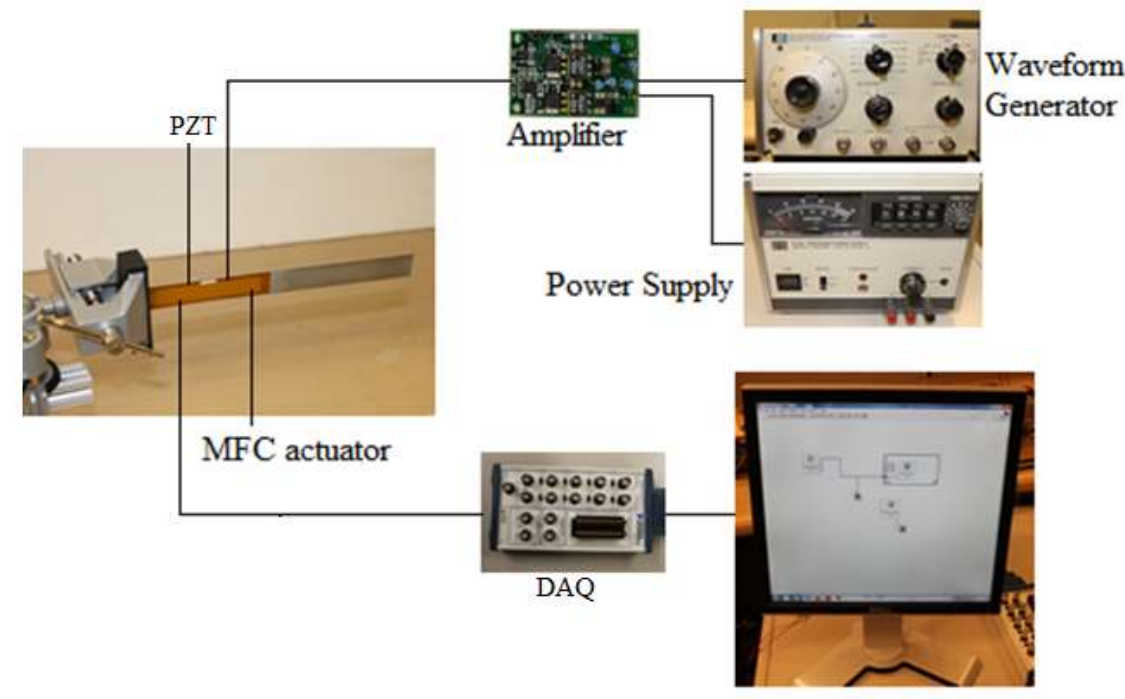

Figure 3. Experimental Setup

LabVIEW is used to analyze the response of the beam to a sine sweep excitation. The computed power spectrum is shown in Figure 4 from which the first 5 natural frequencies are determined. A comparison of the natural frequencies obtained using the analytical model, finite element method, and experiment are provided in Table 4. 


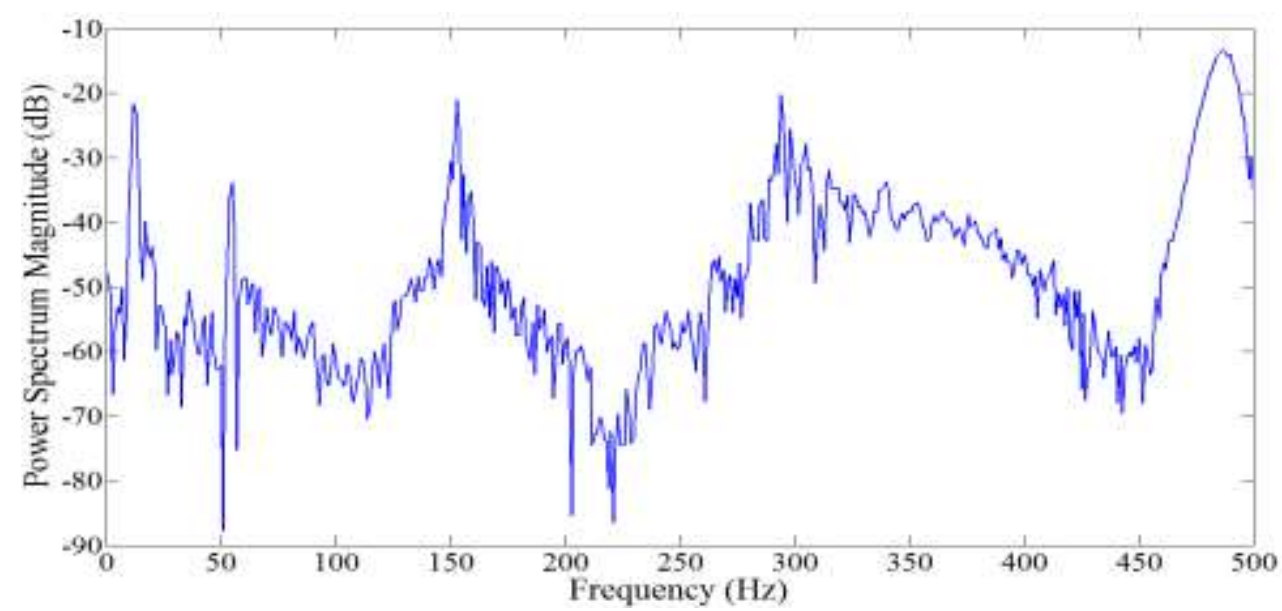

Figure 4. Power Spectrum Analysis of the Cantilever Beam

Table 4. Comparison of the Natural Frequencies of the Beam $(\mathrm{Hz})$

\begin{tabular}{|c|c|c|c|}
\hline Mode \# & Analytical model & Finite element model & Experiment \\
\hline 1 & 8.50 & 8.55 & 9.78 \\
\hline 2 & 53.25 & 53.60 & 54.12 \\
\hline 3 & 149.07 & 150.12 & 152.35 \\
\hline 4 & 291.88 & 294.43 & 294.65 \\
\hline 5 & 482.98 & 487.32 & 488.19 \\
\hline
\end{tabular}

It can be seen from Table 4 that the experimentally determined natural frequencies are slightly higher than those predicted by both the analytical model and the finite element model. Most likely, this small difference is caused by the manner in which the cantilever beam is clamped (the experimental beam is $1 \mathrm{~cm}$ longer so it could be clamped) and also due to the epoxy used to attach the MFC actuator and the PZT sensor, which added stiffness to the structure. This additional stiffness, which is not accounted for in the analytical or finite element models (i.e., perfect bonding was assumed), slightly alters the natural frequencies.

\subsection{Experimental Measurement of Tip Deflection}

To measure the static tip deflection, a highly sensitive Microtrack laser sensor is mounted near the aluminum beam clamps. The support software for the Microtrack laser is set so that it can measure displacement with respect to time. A DC voltage ranging between $2.5 \mathrm{~V}$ to $5 \mathrm{~V}$ is supplied to the high-voltage amplifier, which converts the DC voltage to a voltage range between $0 \mathrm{~V}$ and $1500 \mathrm{~V}$. The deflection of the aluminum cantilever beam is measured for several driving voltages using the Microtrack laser. The laser is aimed at the tip of the cantilever beam to get a precise value.

Figure 5 provides a comparison of the experimental static tip deflection with the predicted static deflection levels from the analytical and finite element models. For both the analytical and finite element analyses, the cantilever beam deflection is approximately a linear function of applied voltage and both models predict similar deflection values. It should be noted, however, that the experimental deflections are significantly smaller than those predicted by the models. This discrepancy is likely due to the effects of clamping the beam, the accuracy of the amplifier in providing the specified driving voltage, and the precision in aiming the laser sensor. 


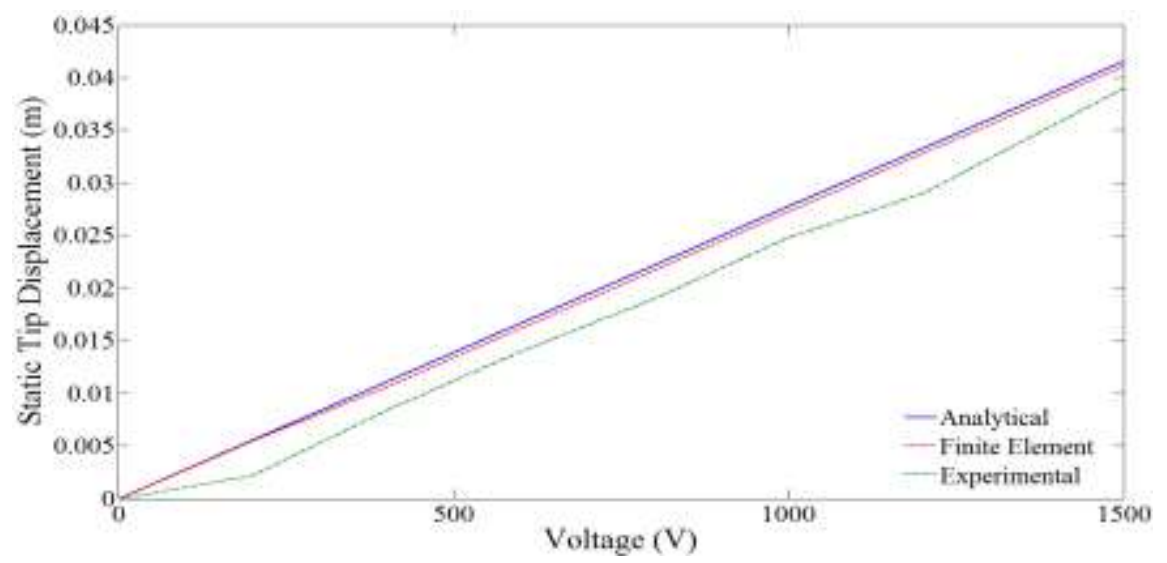

Figure 5. Static Deflection Comparison between the Analytical Model, Finite Element Model, and Experiments

The harmonic tip displacement results obtained from the analytical model, the finite element model, and the experiments, subject to harmonic excitation at the first 3 natural frequencies, are summarized in Table 5. These results show a general agreement between the three approaches, which indicates that the MFC finite element model is reasonably accurate $(0.9 \%$ difference). Differences between the analytical and experimental results can likely be attributed to the factors mentioned previously for the static case in addition to possible inaccuracies in the damping estimation.

Table 5. Comparison of the Harmonic Tip Deflection

\begin{tabular}{|c|c|c|c|}
\hline Frequency (Hz) & Analytical model (m) & Finite element model (m) & Experiment \\
\hline 9.78 & 0.11 & 0.119 & 0.092 \\
\hline 54.12 & 0.01 & $7.17 \mathrm{e}-3$ & $6.3 \mathrm{e}-3$ \\
\hline 152.4 & $1.1 \mathrm{e}-3$ & $7.6 \mathrm{e}-4$ & $7.0 \mathrm{e}-4$ \\
\hline
\end{tabular}

\section{Wing De-Icing Application}

The results presented in Section 4 demonstrate the validity of the MFC finite element model. The application of MFC actuators to the de-icing of a leading edge wing structure was then investigated using finite element analysis. The study first examines the natural frequencies and excitation modes of the leading edge structure. Then, a parametric study for different variables pertaining to the implementation of the MFC actuators is performed in order to increase the efficiency of the proposed technique as well as to minimize the power consumption. These variables include the placement, orientation, number, and thickness of the MFC actuators used for the de-icing application. Finally, an investigation of the de-bonding of ice layers of varying thickness is discussed. 


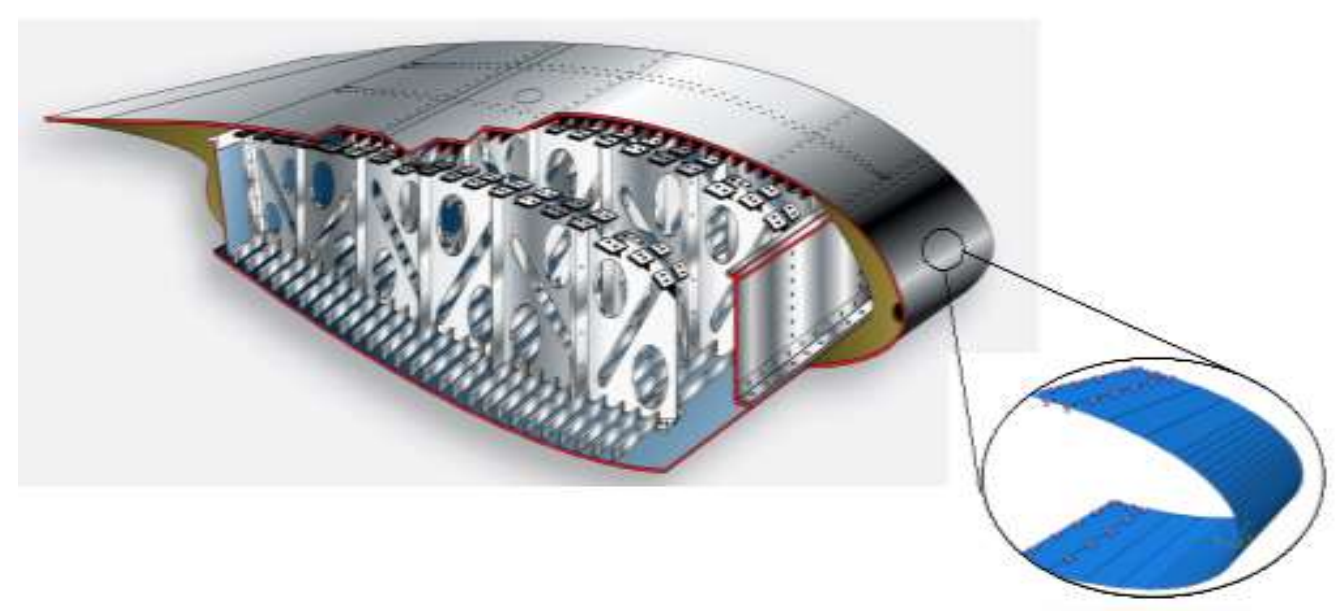

Figure 6. Typical Wing and Leading Edge Model with Fixed Flat Edges [31]

An aluminum leading edge corresponding to the NACA 0024 airfoil geometry is modeled in ABAQUS. The maximum thickness of the leading edge cross-section is 9.45 in $(0.24 \mathrm{~m})$ at $24 \%$ of the chord length. The width and the thickness of the sheet are 11.811 in $(0.3 \mathrm{~m})$ and 0.000295 in $\left(0.75 \times 10^{-3} \mathrm{~m}\right)$, respectively. It should be noted that this thickness is considered due to the fact that the wing leading edge thickness of a Cessna aircraft, which is chosen as an example in this paper, is about 0.02 in (Models 172, 182, T182, 206 and T206) [32]. Because of the manner in which the MFC actuators locally apply force to the structure, there are no analytical models to calculate a reasonable prediction of the shear stresses, natural frequencies, and the mode shapes. Therefore, this de-icing investigation is performed using only finite element analysis, which emphasizes the importance of the finite element model validation performed in Section 4.

\subsection{Wing Leading Edge Model}

To model the leading edge, an 8-node doubly-curved thick shell with reduced integration is used (i.e., S8R). The nodes of the two flat edges of the leading edge, which would be connected to a rigid wing afterbody, are fixed and given zero degrees of freedom (i.e., ENCASTRE) as shown in Figure 7. Because the mesh is relatively coarse, the accuracy of the solution can be ensured by using second-order elements. In this model, 1120 total elements are generated on the leading edge. Modal analysis is performed to obtain the first six natural frequencies and mode shapes of the leading edge. The first six computed natural frequencies are given in Table 6 and their corresponding mode shapes are depicted in Figure 8. 


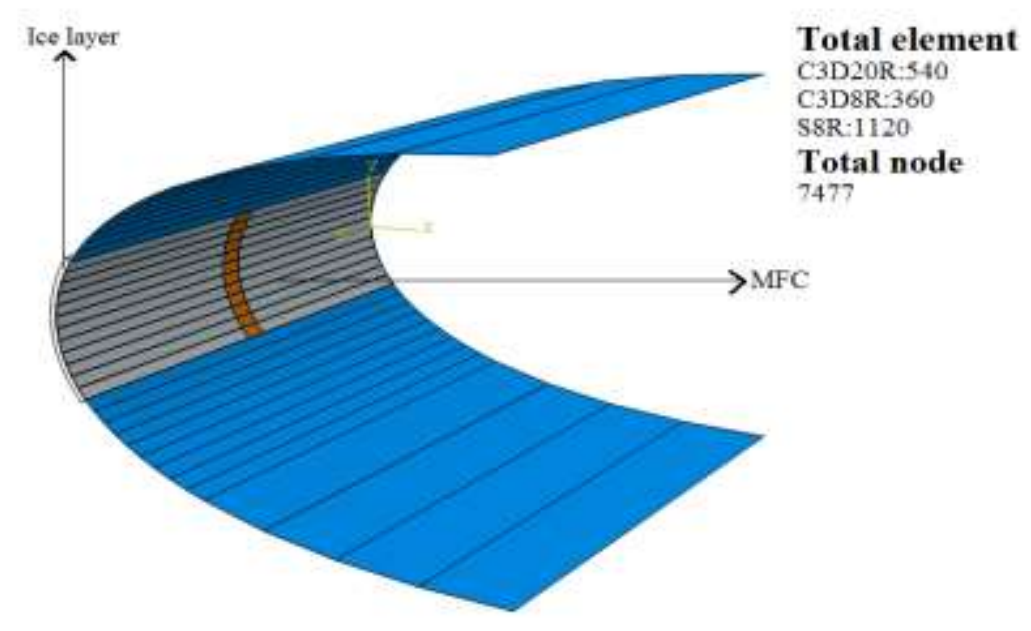

Figure 7. Finite Element Model of a Wing Leading Edge for the De-icing Application

Table 6. Natural Frequencies from the Finite Element Model

\begin{tabular}{|c|c|}
\hline Mode \# & Frequency (Hz) \\
\hline 1 & 21.555 \\
\hline 2 & 59.125 \\
\hline 3 & 64.190 \\
\hline 4 & 105.93 \\
\hline 5 & 113.77 \\
\hline 6 & 162.82 \\
\hline
\end{tabular}




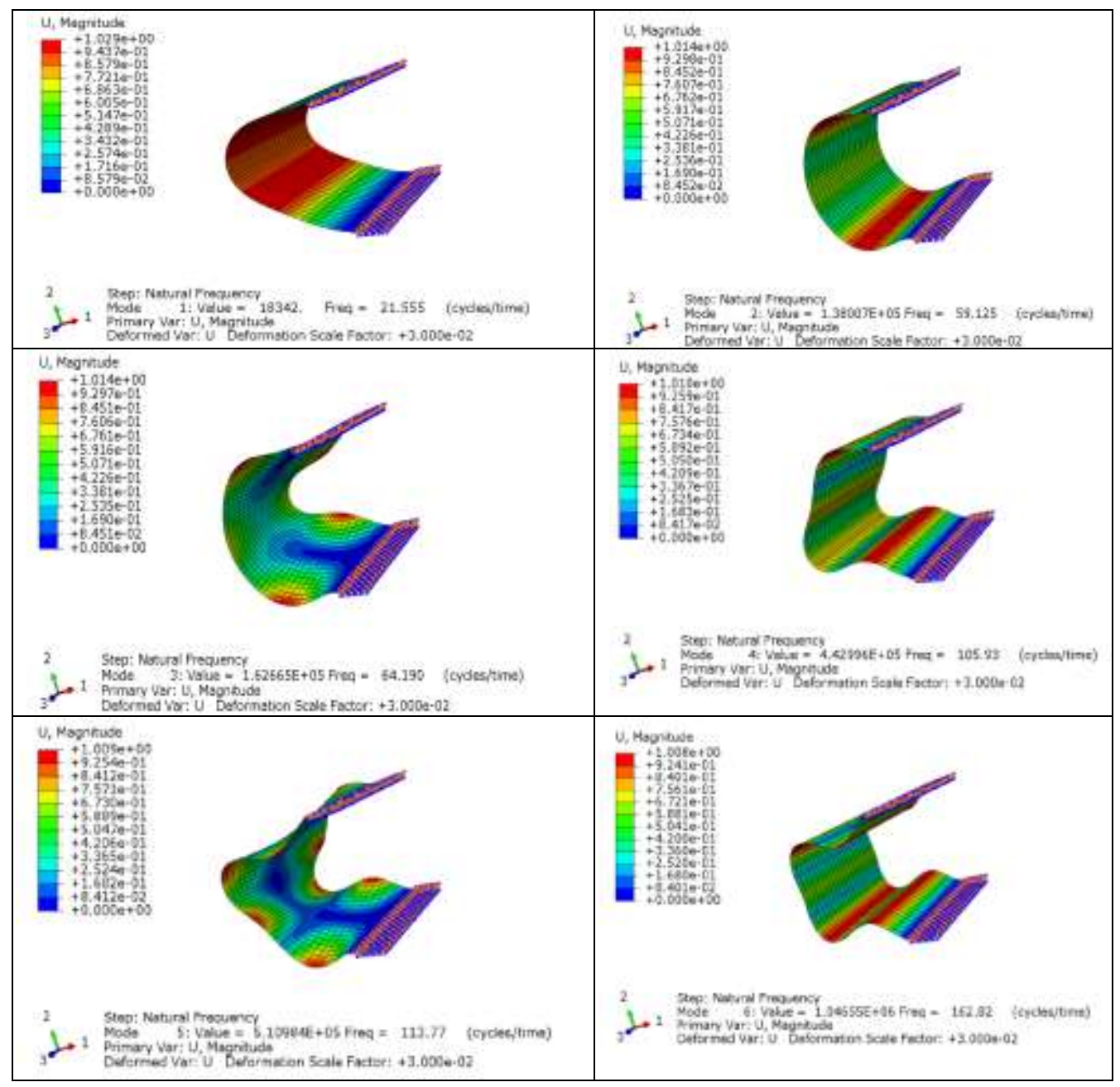

Figure 8. First Six Mode Shapes from Leading Edge Finite Element Model

\subsection{Excitation Modes and MFC Actuator Placement}

An investigation is performed to find the most effective excitation mode and the best placement of the MFC actuators to achieve this modal excitation. For this purpose, an ice layer and an MFC actuator are modeled and added to the leading edge structure. The ice layer is modeled using an 8 node linear brick with reduced integration (i.e., C3D8R). The ice is distributed so that it covers the entire tip surface of the leading edge (see Figure 7) because this surface is the first to be exposed to the wind. The type P1 MFC actuators are modeled using the same mechanical properties and techniques described in Section 3. The mechanical and geometric properties of the ice layer are as follows: $L=8.5 \mathrm{E}-02 \mathrm{~m}$, $W=0.3 \mathrm{~m}, t=4 \mathrm{E}-03 \mathrm{~m}, \rho=917 \mathrm{~kg} / \mathrm{m}^{3}, v=0.31$, and $E=9 \mathrm{E} 9 \mathrm{~Pa}$.

The MFC actuator and the ice layer are bonded to the leading edge structure using the tie constraint. No epoxy layers are considered and the bonding is assumed to be perfect. The MFC actuator is placed in six different locations in order to determine the best combination of excitation mode and actuator location. Because the stiffness and the mass of the structure change with the addition of an ice layer and an MFC actuator, a second modal analysis is performed to extract the modified natural frequencies and mode shapes. Six different MFC actuator locations are considered for the analysis as illustrated in Figure 9. The natural frequencies for the first 6 mode shapes with respect to the actuator locations are given in Table 7. Comparing the natural frequencies given in Tables 6 and 
7 , it is clear that the additional mass of the ice layer and actuator does alter the natural frequencies. It is also evident from Table 7 that the MFC actuator location has a negligible effect on the natural frequencies.

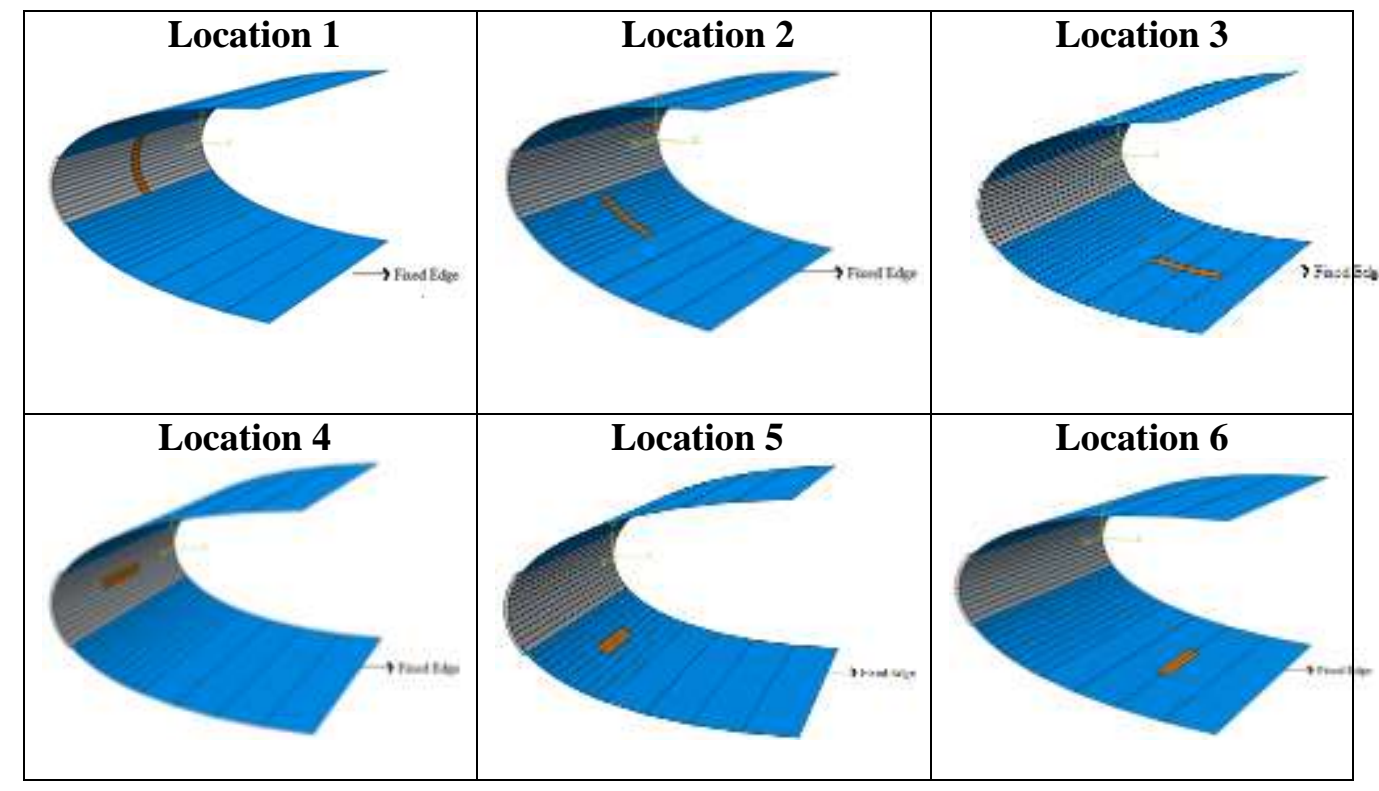

Figure 9. MFC Actuator Locations

Table 7. Natural Frequency of the Leading Edge Structure with Ice Layer for Various MFC Actuator Locations (Hz)

\begin{tabular}{|c|c|c|c|c|c|c|}
\hline Mode \# & $\mathbf{1}$ & $\mathbf{2}$ & $\mathbf{3}$ & $\mathbf{4}$ & $\mathbf{5}$ & $\mathbf{6}$ \\
\hline Location 1 & 18.35 & 69.46 & 69.86 & 105.3 & 139 & 200.1 \\
\hline Location 2 & 18.35 & 69.54 & 69.78 & 105.3 & 138.9 & 199.2 \\
\hline Location 3 & 18.43 & 69.57 & 69.79 & 105 & 139 & 199.1 \\
\hline Location 4 & 18.36 & 69.45 & 69.86 & 105.4 & 139 & 200.1 \\
\hline Location 5 & 18.34 & 69.54 & 69.86 & 105.3 & 138.9 & 198.9 \\
\hline Location 6 & 18.42 & 69.56 & 69.84 & 105.12 & 138.93 & 198.7 \\
\hline
\end{tabular}

In order to determine the most effective combination of excitation mode and MFC actuator location for the de-icing application, a sinusoidal electric potential of $1500 \mathrm{~V}$ is applied to the MFC actuator at the natural frequencies of the structure, as listed in Table 7. The damping ratio of the aluminum leading edge is modeled as 0.15 [33]. For each of the six actuator locations shown in Figure 9, the structure is excited at its natural frequencies and the response of the structure was then evaluated through the shear stress contour plot of the ice layer surface. This surface represents the interface between the aluminum leading edge and the ice layer. The maximum shear stresses generated in the structure due to the MFC actuation are listed in Table 8. 
Table 8. Maximum Shear Stress (MPa) on the Ice Surface for Different Excitation Modes and MFC Actuator Locations

\begin{tabular}{|c|c|c|c|c|c|c|}
\hline Mode \# & $\mathbf{1}$ & $\mathbf{2}$ & $\mathbf{3}$ & $\mathbf{4}$ & $\mathbf{5}$ & $\mathbf{6}$ \\
\hline Location 1 & 0.131 & 0.0952 & 17.65 & 0.131 & 0.13 & 11.46 \\
\hline Location 2 & 3.889 & 0.0424 & 134 & 4.82 & $4.6 \mathrm{e}-3$ & 20.26 \\
\hline Location 3 & 3.028 & 0.075 & 12.87 & 1.483 & $9.54 \mathrm{e}-4$ & 10.89 \\
\hline Location 4 & 0.0279 & 0.03 & 123 & 0.0279 & 0.0278 & 6.56 \\
\hline Location 5 & 1.806 & 6.911 & 7.7 & 1.357 & $7.27 \mathrm{e}-3$ & 13.78 \\
\hline Location 6 & 3.06 & $1.611 \mathrm{e}-3$ & 2.06 & 2.88 & $7.2 \mathrm{e}-4$ & 11.18 \\
\hline
\end{tabular}

According to the results in Table 8, the highest levels of shear stress are generated when Modes 3 and 6 are excited. It is also clear from the results that Location 2 provides the most effective excitation of Modes 3 and 6, and is therefore the best choice out of the $6 \mathrm{MFC}$ actuator locations considered. The third mode is chosen for the de-icing method instead of the sixth mode because the shear stresses generated in Mode 3 are higher than those generated in Mode 6. Hence, it can be concluded from this study that Location 2, where the actuator is attached at the center of the leading edge inner surface at 7.8 in $(0.2$ m) from the fixed edge (see Figure 9), provides the most effective excitation of the third mode, which in turn maximizes the shear stress to provide the most effective de-icing. Figure 10 shows the shear stress distribution over the ice layer that is achieved by exciting the structure at the Mode 3 natural frequency of $69.8 \mathrm{~Hz}$ with an MFC actuator at Location 2.
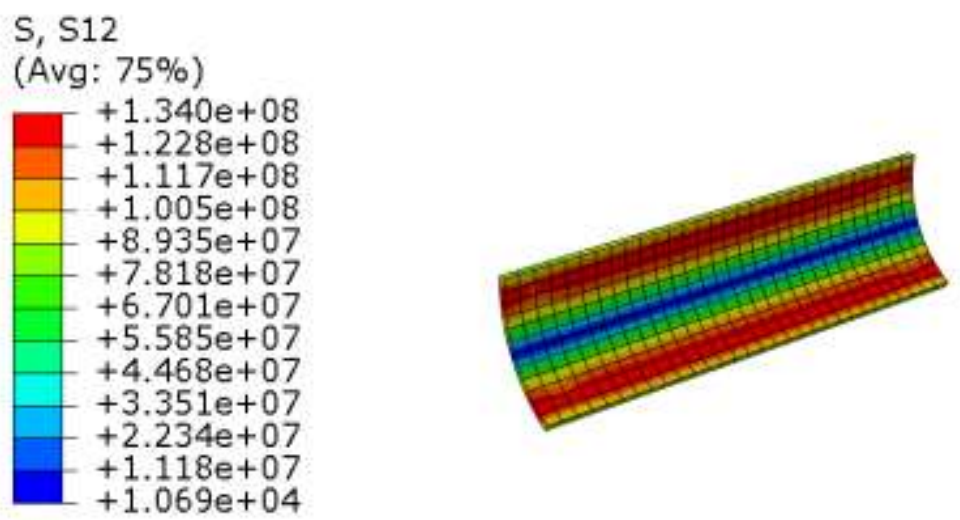

Figure 10. Shear Stress Distribution (Pa) over the Ice Layer for Mode 3 Excitation using an MFC Actuator at Location 2

\subsection{Distribution of MFC Actuators}

After determining the most effective excitation mode and MFC actuator placement for the proposed de-icing technique, several MFC actuator distributions, corresponding to varying the number and spacing of the actuators in the vicinity of Location 2, are then analyzed. The six MFC actuator distributions shown in Figure 11 are all modeled and subjected to excitation at the Mode 3 natural frequency. Table 9 summarizes the results of this study, showing the maximum shear stress achieved for each actuator distribution. Table 9 also shows the variation in the Mode 3 natural frequency for each distribution. There is very little variation in the frequency for the different distributions because the mass of the MFC actuators is quite small compared to that of the leading edge structure and ice layer. 


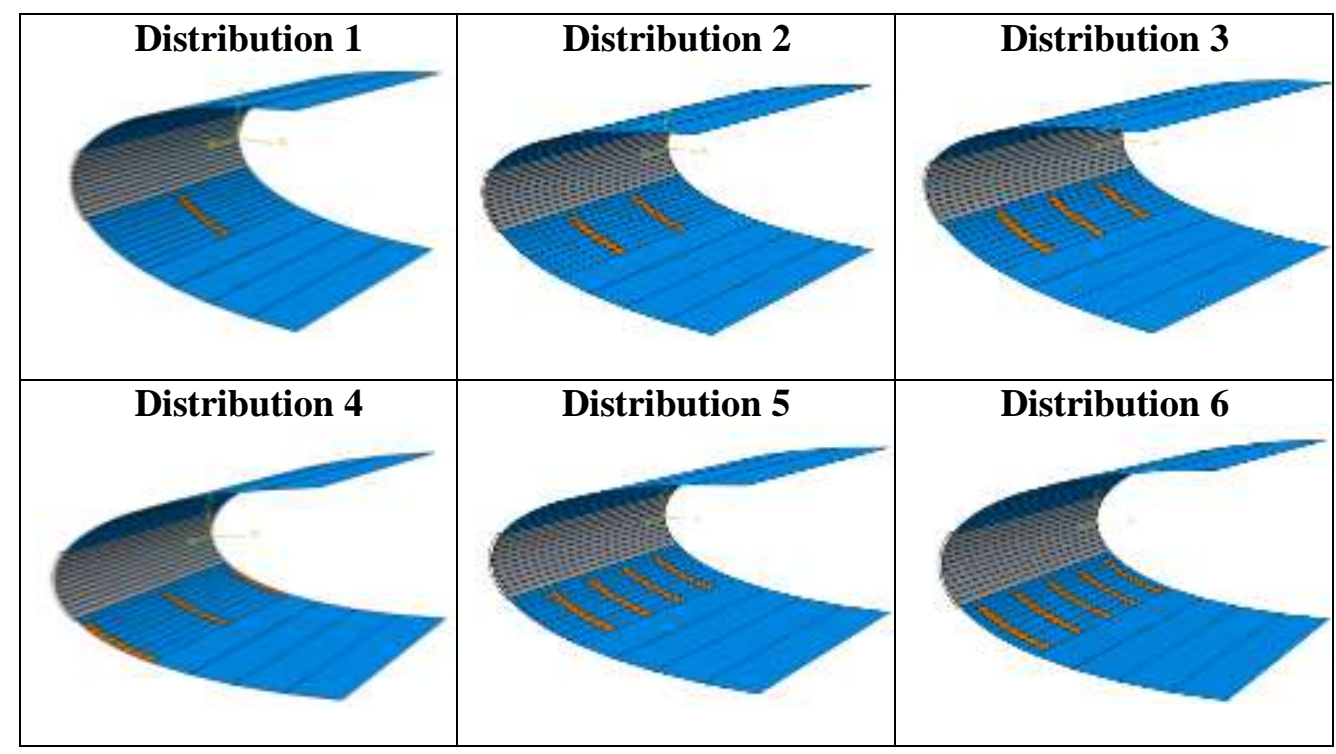

Figure 11. MFC Actuator Distributions

Table 9. Maximum Shear Stresses for the Different MFC Actuator Distributions

\begin{tabular}{|c|c|c|}
\hline Mode 3 & Natural Frequency (Hz) & Shear Stress (MPa) \\
\hline Distribution 1 & 69.78 & 134 \\
\hline Distribution 2 & 69.58 & 28.14 \\
\hline Distribution 3 & 69.39 & 146.3 \\
\hline Distribution 4 & 69.39 & 1.294 \\
\hline Distribution 5 & 69.21 & 62.86 \\
\hline Distribution 6 & 69.02 & 121.2 \\
\hline
\end{tabular}

From the results in Table 9, it can be concluded that Distribution 3, which consists of three MFC actuators with equal spacing centered on Location 2, provides the maximum shear stress and is the most effective option for the de-icing application.

\subsection{Effect of MFC Actuator Width}

Following the determination that Distribution 3 provides the most effective distribution of MFC actuators for de-icing with Mode 3 excitation, the effect of varying the MFC actuator width is investigated. Three choices of MFC width, corresponding to 1.4, 2.8 and $5.7 \mathrm{~cm}$, were considered as shown in Figure 12. Table 10 presents the natural frequencies as well as the maximum shear stress generated for the different choices of actuator width for Mode 3 excitation with MFC actuators arranged as in Distribution 3. 


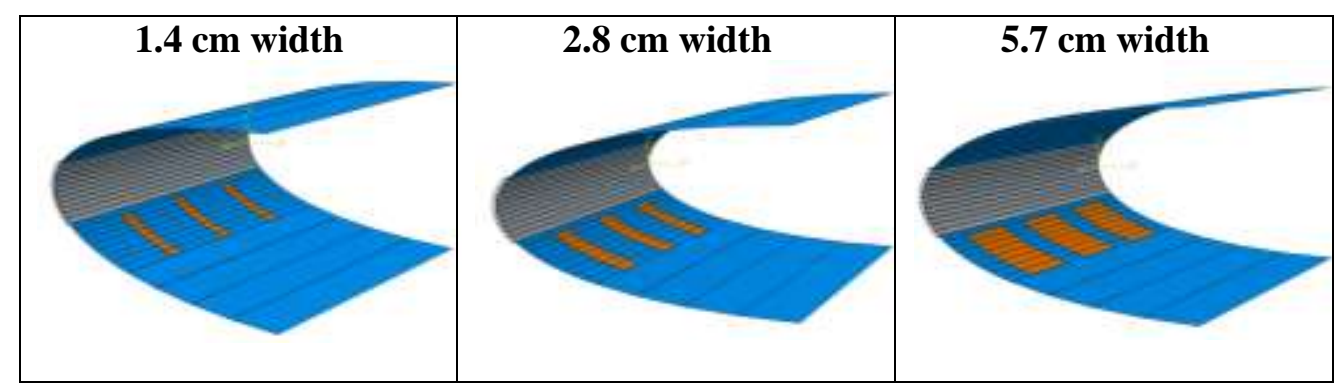

Figure 12. Variation in MFC Actuator Width

Table 10. Maximum Shear Stress for Varying MFC Actuator Width

\begin{tabular}{|c|c|c|}
\hline Mode 3 & Natural frequency $\mathbf{( H z )}$ & Shear stress (MPa) \\
\hline $\mathbf{1 . 4}$ cm width & 69.39 & 146 \\
\hline $\mathbf{2 . 8}$ cm width & 68.87 & 1.7 \\
\hline 5.7 cm width & 67.93 & 0.688 \\
\hline
\end{tabular}

The results in Table 10 show that the maximum shear stress generated by $1.4 \mathrm{~cm}$ width MFC actuators is two orders of magnitude higher than that generated by the two wider actuator options that are considered. These results are due to the fact that increasing the actuator width from $1.4 \mathrm{~cm}$ to $2.8 \mathrm{~cm}$ or $5.7 \mathrm{~cm}$ causes the third mode shape to become asymmetric, which leads to very small levels of shear stress.

The overall conclusion from this trade study is that, of all the configurations that are considered, the most effective implementation of MFC actuators for de-icing corresponds to exciting the structure at the Mode 3 natural frequency of $69.4 \mathrm{~Hz}$ with $1.4 \mathrm{~cm}$ width MFC actuators arranged according to Location 2 and Distribution 3, as shown in Figure 13.

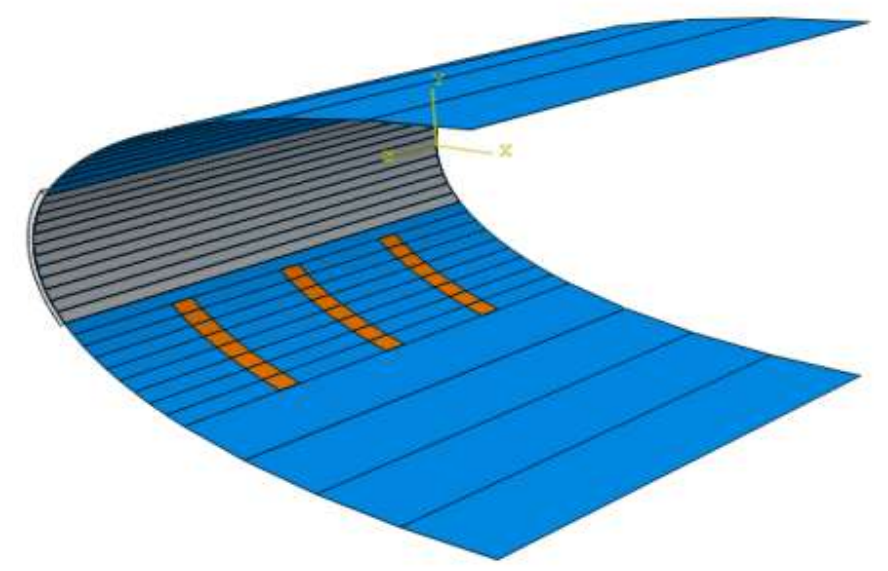

Figure 13. Ultimate Arrangement of MFC Actuators (Location 2 and Distribution 3) 


\subsection{Ice De-Bonding Analysis}

An ice de-bonding study is then performed to determine if the MFC de-icing configuration would produce sufficient shear stresses to de-ice the leading edge for varying levels of ice thickness. According to Archer and Gupta [19], the minimum adhesive shear stress required to de-bond ice from an aluminum surface is $1.6 \mathrm{MPa}$; hence when the shear stress distribution on the ice surface exceeds 1.6 MPa, de-bonding should occur. A summary of the structural response for different levels of ice thickness is given in Table 11. The results show that the natural frequency of Mode 3 decreases as the ice thickness increases, and in all cases, the level of shear stress generated is at least $22 \mathrm{MPa}$.

Table 11. Summary of De-Bonding Analysis for Varying Ice Thickness

\begin{tabular}{|c|c|c|c|}
\hline Mode 3 & Natural frequency (Hz) & Shear stress (MPa) & $\begin{array}{c}\text { De-Bonding } \\
\text { (Yes/No) }\end{array}$ \\
\hline 4 mm of ice & 69.39 & 146 & Yes \\
\hline 5 mm of ice & 68.77 & 25.8 & Yes \\
\hline 6 mm of ice & 67.96 & 35.2 & Yes \\
\hline 7 mm of ice & 67.1 & 22.7 & Yes \\
\hline 8 $\mathbf{~ m m ~ o f ~ i c e ~}$ & 66.33 & 22 & Yes \\
\hline
\end{tabular}

\subsection{Power Consumption}

The power required for the proposed de-icing technique is considered for a single MFC actuator, which is given as [34]:

$$
P_{\max }=\pi C V_{\max } V_{P . P} f
$$

The capacitance $C$ of the MFC actuators considered in this study is $3 \mathrm{nF}$ [25]. The applied peak to peak voltage $V_{P . P}$. is $2000 \mathrm{~V}(-500 \mathrm{~V}$ to $+1500 \mathrm{~V})$, the maximum voltage $V_{\max }$ of the amplifier is $1500 \mathrm{~V}$, and the excitation frequency $f$ is roughly $69.2 \mathrm{~Hz}$. Therefore, according to Eq. (13), the power consumption of each MFC actuator is 1.956 W. Since three MFC actuators are employed for de-icing, the total power consumption is $5.868 \mathrm{~W}$ for this configuration.

In order to operate the MFC actuators, high-voltage amplifiers are required as discussed in Section 4. The maximum output power for each amplifier cannot exceed 4 $\mathrm{W}$ [25]; therefore it is not desirable to connect two MFC actuators to the same amplifier (power consumption for two MFCs is $3.912 \mathrm{~W}$ ). As a result, three actuators require the use of three high-voltage amplifiers. Since each amplifier requires $1.4 \mathrm{~W}$ to generate maximum output voltage [19], the total power consumption for the proposed de-icing technique is $4.2 \mathrm{~W}$. The surface area of the tested leading edge is $0.9 \mathrm{ft}^{2}\left(0.0837 \mathrm{~m}^{2}\right)$, so the total power consumption for the proposed technique is approximately $4.2 \mathrm{~W} / \mathrm{ft}^{2}\left(51.18 \mathrm{~W} / \mathrm{m}^{2}\right)$.

\section{Conclusion}

This paper has discussed a technique for the in-flight de-icing of the leading edge of an aircraft wing using lightweight macro-fiber composite (MFC) actuators to break the adhesive bond between an accumulated ice layer and the leading edge structure. The proposed de-icing technique relies on the fact that when a structure is excited at its natural frequencies, the shear stress generated is largest at certain modes of vibration. A finite element analysis is performed to evaluate the effectiveness of the MFC-based de-icing strategy. In order to conduct this analysis, it is necessary to first develop a finite element model of MFC actuator since no such model exists in standard finite element software 
packages. The MFC finite element model is developed via a modification of the standard piezoceramic finite element model that is available in ABAQUS. This model is then validated on a unimorph cantilever beam system for which an analytical model is readily available. The validation process consists of comparing results obtained from the finite element model with those obtained analytically and through experimentation.

Following the successful validation of the MFC finite element model, a model of the aluminum leading edge of an airfoil is developed in order to study the MFC-based deicing technique. Finite element analysis is first used to determine the natural frequencies of the structure. Then, in order to determine the most effective mode of excitation for the de-icing application, the finite element model is used to compute the shear stresses generated at the leading edge when the structure is excited at each of the first six natural frequencies. This analysis indicates that excitation of the third mode would generate the largest shear stresses at the leading edge and, therefore, would provide the most effective de-icing. Further analysis is conducted to determine the best location, number, and width of the MFC actuators for exciting the third mode of the structure. It can be concluded that, based on the set of configurations considered, the best combination of these parameters corresponds to placing three $1.4 \mathrm{~cm}$ wide MFC actuators on the inner surface of the leading edge at $20 \mathrm{~cm}$ from the fixed edge. The spacing between these actuators is 6.45 $\mathrm{cm}$. This actuator configuration generates a shear stress of $146 \mathrm{MPa}$, which is two orders of magnitude larger than the $1.6 \mathrm{MPa}$ required to de-bond the ice from the wing leading edge. Varying levels of ice thickness up to $8 \mathrm{~mm}$ are also studied and it is shown that debonding is achieved in all the cases considered. The total power consumption for the proposed de-icing technique is found to be $51.18 \mathrm{~W} / \mathrm{m}^{2}$.

The proposed MFC-based de-icing method offers several potential advantages compared to other de-icing techniques currently in use:

1. Lower weight: The weight of each high-voltage amplifier is 14 grams and each MFC actuator is 2 grams, which makes a total weight of 48 grams for three MFC actuators with amplifiers. This weight is negligible compared to the weight of deicing boots or heating systems.

2. Power consumption: The total power consumption is $51.18 \mathrm{~W} / \mathrm{m}^{2}$, which is very low compared to thermal techniques.

3. Airfoil aerodynamics: The MFC actuators can be bonded to the inner surface of the leading edge; therefore, they do not change the shape of the airfoil and hence they do not affect the aerodynamic performance of the aircraft.

4. Ease of attachment: the MFC actuators are very flexible and can be attached easily to a curved leading edge surface.

While MFC actuators hold considerable potential for aircraft de-icing applications, further investigation on the implementation of MFC-based de-icing systems is required. The finite element analysis can be extended to consider the modeling of the ice layer attached to the wing structure. Then, ice de-bonding in response to MFC actuation can be simulated, providing insight into the physics of the de-bonding process as opposed to merely measuring the maximum shear stress. Experimental studies should be performed to validate the results of the finite element analysis with regards to actuator placement and excitation frequency. In addition, the dynamic response of the MFC-based de-icing system should be measured, including the time required for ice de-bonding to occur.

\section{Acknowledgements}

The first author would like to acknowledge Dr. Lihua Tang from Nanyang Technological University for all his advice and suggestions regarding the finite element modeling of MFC, which have been greatly appreciated. 


\section{References}

[1] F.T. Lynch and A. Khodadoust, "Effects of Ice Accretions on Aircraft Aerodynamics," Progress in Aerospace Sciences, vol. 37, no. 8, (2001), pp. 669 - 767.

[2] S. Lee and M.B. Bragg, "Investigation of Factors Affecting Iced-Airfoil Aerodynamics," Journal of Aircraft, vol. 40, no. 3, (2003), pp. 499 - 508.

[3] Preliminary Data Summary Airport Deicing Operations (Revised), Environmental Protection Agency, (2000).

[4] F. Caliskan, and C. Hajiyev, "A Review of In-Flight Detection and Identification of Aircraft Icing and Reconfigurable Control,” Progress in Aerospace Sciences, Vol. 60, (2013), pp. 12 - 34.

[5] J. J. Reinmann, R. J. Shaw and R. J. Ranaudo, "NASA's Program on Icing Research and Technology," Proceedings of the Symposium on Flight in Adverse Environmental Conditions, Kluwer Publishers, Norwell, MA, (1989), pp. $73-78$.

[6] www.coxandco.com/products/low_power_ice_protection_systems.html. Company website for Cox \& Company, Inc., Low Power Ice Protection Systems, (Accessed 15 August 2015).

[7] C.A. Martin and J.C. Putt, "Advanced Pneumatic Impulse Protection System (PIIP) for Aircraft," Journal of Aircraft, vol. 29, no. 4, (1992), pp. 714-716.

[8] R. B. Ingram, and J. J. Gerardi, "Shape Memory Alloy De-Icing Technology," U.S. Patent Number: $5,686,003,(1997)$.

[9] S. Venna and Y. J. Lin, "Mechatronic Development of Self-Actuating In-Flight Deicing Structures," IEEE/ASME Transactions on Mechatronics, vol. 11, no. 5, (2006), pp. $585-592$.

[10] S. Venna, Y. Lin and G. Botura, "Piezoelectric Transducer Actuated Leading Edge De-Icing with Simultaneous Shear and Impulse Forces," Journal of Aircraft, vol. 44, no. 2, (2007), pp. 509 - 515.

[11] S. Struggl, J. Korak and C. Feyrer, "A Basic Approach for Wing Leading Edge Deicing by Smart Structures," Proceedings of the SPIE, Sensors and Smart Structures Technologies for Civil, Mechanical, and Aerospace Systems, 79815L, (2011).

[12] S.B. Kandagal and K. Venkatraman, "Piezo-Actuated Vibratory Deicing of a Flat Plate," $46^{\text {th }}$ AIAA/ASME/ASCE/AHS/ASC Structures, Structural Dynamics \& Materials Conference, Austin, TX, AIAA 2005-2115, (2005).

[13] S. Ramanathan, V. V. Varadan and V. K. Varadan, "Deicing of Helicopter Blades using Piezoelectric Actuators," Proceedings of the SPIE, Smart Structures and Materials 2000: Smart Electronics and MEMS, vol. 3990, (2000), pp. $281-292$.

[14] W.K. Wilkie, R.G. Bryant, J.W. High, R.L. Fox, R.F. Hellbaum, A. Jr., Jalink, B.D. Little, P.H. Mirick, "Low-Cost Piezocomposite Actuator for Structural Control Applications," Proceedings of the SPIE 3991, Smart Structures and Materials 2000: Industrial and Commercial Applications of Smart Structures Technologies, 323, Hampton, Virginia, (2000).

[15] E. F. Sheta, R. W. Moses and L. J. Huttsell, "Active Smart Material Control System for Buffet Alleviation," Journal of Sound and Vibration, vol. 292, (2006), pp. 854-868.

[16] O. Bilgen, K. Kochersberger, E. C. Diggs, A. J. Kurdila, and D. J. Inman, "Morphing Wing Micro AirVehicles via Macro-Fiber-Composite Actuators," ASME / Boeing Best Paper Award, AIAA-2007-1785, 48th AIAA/ASME/ASCE/AHS/ASC Structures, Structural Dynamics, and Materials Conference, Honolulu, HI, (2007).

[17] H.A. Sodano, G. Park and D.J. Inman, "An Investigation into the Performance of Macro-Fiber for Sensing and Structural Vibration Applications", Mechanical Systems and Signal Processing, vol. 18, (2004), pp. $683-697$.

[18] www.Americanpiezo.com: Company website for APC International, Ltd. (Accessed 10 August 2014).

[19] www.smartmaterialscorp.com: Company website for Smart Materials Corporation. (Accessed 10 August 2014).

[20] W. Wang, and Z. Yang, "Asymmetric Temperature Load Method for Simulation Study of Wing Leading Edge in Flight Deicing with MFC," International Journal of Control and Automation, vol. 6, no. 6, (2013), pp. $359-370$.

[21] L.E. Raraty and D. Tabor, "The Adhesion and Strength Properties of Ice," Proceedings of the Royal Society of London, 245A, (1958), pp.184-201.

[22] D.L. Loughborough, "The Physics of Mechanical Removal of Ice from Aircraft," Aeronautical Engineering Review, (1952), pp. 29 - 34.

[23] W.D. Bascom, R.L. Cottintone and C.R. Singleterry, "Ice Adhesion to Hydrophilic and Hydrophobic Surfaces," Journal of Adhesion, vol.1, (1969), pp.246-263.

[24] H.H.G. Jellinek, "Adhesive Properties of Ice," USA Cold Regions Research and Engineering Laboratory, Research Report 38, AD-149061, (1957).

[25] P. Archer and V. Gupta, "Measurement and Control of Ice Adhesion to Aluminum 6061 Alloy," J. Mech. Phys. Solids, vol. 46, no.10, (1998), 1745-1771.

[26] R. D. Belvins, Formulas of Natural Frequency and Mode Shape, $4^{\text {th }}$ Edition, Robert E. Krieger Publishing Co., FL, (1987). 
[27] V. Tiwari and A.K. Srivastava, "Study of the Tip Deflection in Static State of a Piezoelectric Polymer based Bimorph Actuator with Varying Thickness and Length Ratios," International Journal of Engineering Trends and Technology, vol. 4, no. 6, (2013), pp. $2675-2680$.

[28] A. Mineto, M. De Souza Braoun, H. Navarro and P. Varoto, "Modeling of a Cantilever Beam for Piezoelectric Energy Harvesting," 9th Brazilian Conference on Dynamics, Control and their Applications, Sao Carlos, SP, Brazil, (2010).

[29] ABAQUS Analysis User's Manual, Dassault Systems Simulia Corp., Providence, RI, (2012).

[30] Yang, Yaowen, Tang, Lihua, and Li, Hongyun, "Vibration Energy Harvesting using Macro-Fiber Composites," Smart Materials and Structures, Vol. 18, No. 11, November (2009), 115025.

[31] Chapter 15: Aircraft Structures - FAA. Retrieved from www.faa.gov/regulations_policies/handbooks_ manuals/aircraft/amt_airframe_handbook/media/ama_ch01.pdf.

[32] Service bulletin of single engine, SEB95-3, Cessna, (1995).

[33] D.J. Inman, Engineering Vibration, $2^{\text {nd }}$ edition, Prentice Hall, (2000).

[34] S. Zhou, C. Liang and C.A. Rogers, "Coupled Electro-Mechanical Impedance Modeling to Predict Power Requirement and Energy Efficiency of Piezoelectric Actuators Integrated with Plate-Like Structures," AIAA Paper No. 94-1762, AIAA/ASME Adaptive Structures Forum, Hilton Head, SC, April (1994). 